\title{
Difficult ventilation in a wide congenital tracheoesophageal fistula
}

\author{
Devalina Goswami, MD • Nisha Kachru, MD • \\ Nitin Pant, MCh
}

Received: 31 August 2011/ Accepted: 3 October 2011/Published online: 13 October 2011

(C) Canadian Anesthesiologists' Society 2011

\section{To the Editor,}

Management of tracheoesophageal fistula (TEF) is an anesthetic challenge. It is complicated by respiratory problems and other congenital anomalies that may be present. Successful management of neonates presenting for TEF repair depends on the knowledge and ability of the anesthesiologist. Survival is directly related to adequate treatment. ${ }^{1}$ We report the case of a premature infant diagnosed to have TEF with esophageal atresia in whom we faced considerable difficulty with the initial ventilation. Consent for publication was obtained from the parents.

A 34-week (gestational age) premature infant weighing $1.37 \mathrm{~kg}$ was diagnosed to have TEF with esophageal atresia (type C), and repair was planned. Preoperatively, the patient had bilateral conducted sounds in the chest, the respiratory rate was $58-60 \cdot \mathrm{min}^{-1}$, and oxygen saturation $\left(\mathrm{SpO}_{2}\right)$ was $90 \%$ in room air. No other abnormality was detected clinically.

Inhalational induction was performed with sevoflurane and oxygen. Oxygen saturation improved to $100 \%$ on mask ventilation. After an adequate depth of anesthesia had been reached, the trachea was intubated under direct vision with a $2.5-\mathrm{mm}$ uncuffed endotracheal tube (ETT). On auscultation, bilateral air entry was heard, but the $\mathrm{SpO}_{2}$ then decreased to $80 \%$. The ETT was immediately withdrawn. When mask ventilation was applied, the $\mathrm{SpO}_{2}$ improved. A second attempt at intubation resulted in a similar $\mathrm{SpO}_{2}$ decrease, with accompanying distention of the abdomen. The ETT was again withdrawn, but gradually; when the bevel of the ETT was just inside the glottis, the $\mathrm{SpO}_{2}$

D. Goswami, MD $(\bowtie) \cdot$ N. Kachru, MD $\cdot$ N. Pant, MCh

Lady Hardinge Medical College \& Kalawati Saran

Children Hospital, New Delhi, India

e-mail: drdevalina@gmail.com started to improve. The ETT was fixed, and intermittent positive-pressure ventilation was instituted with a tidal volume of $8 \mathrm{~mL} \cdot \mathrm{kg}^{-1}$ body weight and a rate of 15 breaths $\cdot \min ^{-1}$. After carefully fixing the tube at the site, surgery proceeded uneventfully for $75 \mathrm{~min}$. Intraoperatively, a TEF that was approximately $3 \mathrm{~mm}$ wide, which is nearly the size of the trachea, was identified (Figure). In retrospect, it was thought that the ETT entered the wide fistula during both intubations, which led to the decreased $\mathrm{SpO}_{2}$ and increased abdominal distention.

Maintaining ventilation during TEF repair is a difficult task - even more so when the fistula is broad. Anesthetic and surgical management focuses on ventilating the lungs without ventilating the fistula. This requires maintenance of spontaneous breathing, with avoidance of neuromuscular blocking agents and excessive positive pressure, until the fistula is closed. The ETT should be placed properly, and occasionally gastrostomy is performed, either preoperatively under local anesthesia or soon after induction, to decompress the stomach and prevent gastric distention. ${ }^{2}$

The size of a fistula in a case of congenital TEF varies from a small punctum to the size of a mainstem bronchus. ${ }^{3}$ Our patient's fistula was unusually large and was nearly the size of the trachea. It was difficult to avoid the fistula and insert the tube in the trachea. Auscultating the chest for bilateral air entry may give a false-positive result, as air inflation in the stomach can easily be transmitted to the chest and be mistakenly identified as chest inflation, particularly in small infants.

A Fogarty catheter or a neonatal cuffed tube may be used to occlude a large fistula until it is ligated. ${ }^{4}$ However, fibreoptic bronchoscopy (FOB) is the most reliable technique to confirm placement of an ETT in patients with TEF. ${ }^{5}$ We do not routinely use it, as we have adopted the traditional technique of introducing the ETT into the right 


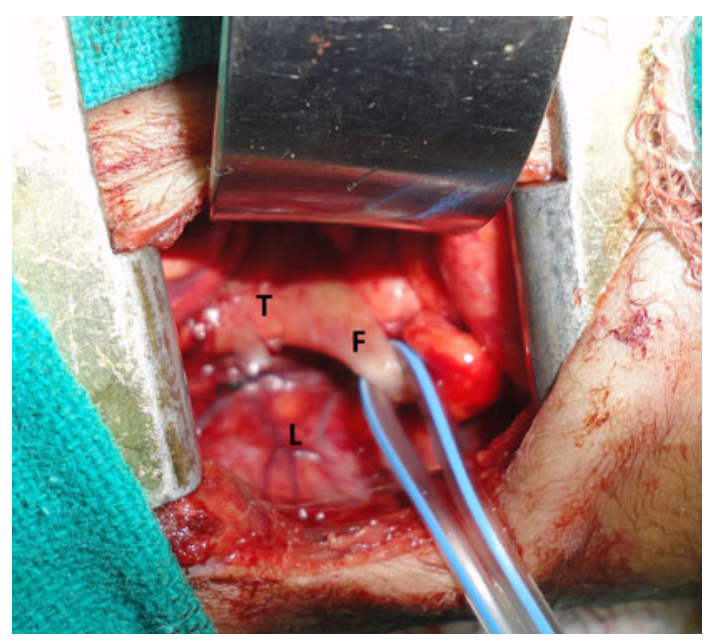

Figure Intraoperative photograph showing the trachea $(\mathrm{T})$ and the wide type $\mathrm{C}$ fistula $(\mathrm{F})$ hooked with an infant feeding tube

main bronchus and then gradually withdrawing it until bilateral air entry is heard, with the assumption that when the tip of the ETT is midway between the carina and the fistula opening the success rate is good. However, rare and difficult cases such as the one reported here highlight the importance of FOB-guided ETT placement.

Competing interests None declared.

\section{References}

1. Gayle JA, Gomez SL, Baluch A, Fox C, Lock S, Kaye A. Anesthetic considerations for neonate with tracheoesophageal fistula. Middle East J Anesthesiol 2008; 19: 1241-54.

2. AndroPoulus DB, Rowe RW, Betts JM. Anaesthetic and surgical airway management during tracheo-oesphageal fistula repair. Paediatr Anaesth 1998; 8: 313-9.

3. Bluestone CD, Stool SE, Alper CM, et al. Pediatric Otolaryngology $4^{\text {th }}$ Edition (volume 2). PA: WB Saunders; 2003: 1282.

4. Gupta A. Tracheo oesophageal fistula oesophageal atresia and anaesthetic management. Indian J Anaesth 2002; 46: 353-5.

5. Horishita T, Ogata J, Minami K. Unique anesthetic management of a patient with a large tracheoesophageal fistula using fiberoptic bronchoscopy. Anesth Analg 2003; 97: 1856. 